\title{
Textural properties of synthetic clay-ferrihydrite associations
}

\author{
R. CELIS, J. CORNEJO AND M. C. HERMOSIN \\ Instituto de Recursos Naturales y Agrobiología de Sevilla, CSIC, PO Box 1052, E-41080 Sevilla, Spain
}

(Received 17 January 1997; revised I December 1997)

\begin{abstract}
Kaolinite-ferrihydrite and montmorillonite-ferrihydrite associations were prepared following a procedure based on the Russell method for the synthesis of ferrihydrite and the texture of the clay-ferrihydrite complexes was studied using different techniques. The textural properties of kaolinite were little affected by the Fe association, showing only a slight increase in the specific surface area measured by nitrogen adsorption and a decrease in the largest pores $(>10 \mu \mathrm{m})$, as measured by mercury porosimetry. In contrast, the nitrogen specific surface area of the montmorillonite complexes was much higher than that of the clay without $\mathrm{Fe}$ and the pore structure depended on the amounts of $\mathrm{Fe}$ in the complexes. Application of the fractal approach to nitrogen adsorption data indicated that the surface roughness (microporosity) was greater for the complexes prepared from diluted $\mathrm{Fe}(\mathrm{III})$ solutions, in agreement with the information obtained from classical interpretation of the adsorption isotherms (shape of the isotherms and t-plots).
\end{abstract}

The applicability of nitrogen adsorption in the study of the specific surface area of clay minerals has been discussed by many authors (Brooks, 1955; Aylmore \& Quirk, 1967; Thomas \& Bohor, 1968; Aylmore et al., 1970; Murray \& Quirk, 1990). Although some have attributed part of the $N$ surface area of montmorillonite to the penetration of $\mathrm{N}_{2}$ molecules into the interlamellar spaces of the clay (Thomas \& Bohor, 1968), it is more accepted that, provided the outgassing of the sample has been successful and the exchangeable cation is not too large, the $\mathrm{N}_{2}$ sorption which does occur appears to be essentially between, rather than into, quasi-crystalline regions of montmorillonite (Aylmore et al., 1970; Quirk \& Aylmore, 1971). The nature of the exchangeable cation in montmorillonite clays and its effects on the pore matrix formed after sample drying have been reported to be the most important factors affecting the final specific surface areas measured by $\mathrm{N}_{2}$ adsorption (Aylmore \& Quirk, 1967; Rutherford et al.,1997). Clays such as kaolinite which are characterized by a low exchange capacity and relatively coarse particle size show little evidence of the relationship between the $\mathrm{N}_{2}$ surface area and either the water content or the nature of the exchangeable cation in the clay.

The recent application of the fractal theory (Mandelbrot, 1982) in studying the pore matrix of solids has been shown to be very useful, because it may describe a pore structure by means of a single parameter, such as its surface fractal dimension, $D_{\mathrm{s}}$. Recently, assuming a fractal pore-size distribution, Avnir \& Jaroniec (1989) and Yin (1991) were able to obtain an adsorption isotherm equation (eqn. 1) which was found to be similar to that obtained by FrenkelHalsey-Hill (Gregg \& Sing, 1982) for multilayer adsorption of gases on a smooth surface (eqn. 2).

$$
\begin{aligned}
& \log \left(\frac{p_{0}}{p}\right)=\mathrm{K}^{\prime} \cdot \theta^{\left(D_{\mathrm{s}}-3\right)^{-1}} \\
& \log \left(\frac{p_{0}}{p}\right)=\mathrm{b} \cdot \theta^{\mathrm{s}}
\end{aligned}
$$

In the above expressions, $\theta$ represents the surface fractional coverage, $p$ and $p_{\mathrm{o}}$ are, respectively, the equilibrium and saturation pressures of the adsorbate, $\mathrm{s}$ is a 'critical' exponent in the FHH equation (eqn. 2), and $D_{\mathrm{s}}$ is the surface fractal dimension in the Avnir and Jaroniec equation (eqn. 1).

Since the assumptions made to obtain the above equations are quite different, the meaning of the 
characteristic parameters, $D_{\mathrm{s}}$ and $\mathrm{s}$, must also be different. Thus, whereas the differences in $s$ values for the adsorption of $\mathrm{N}_{2}$ on two samples are justified by Halsey (1948) in terms of different strengths of interaction between the adsorbate and the two solids, the corresponding $D_{\mathrm{s}}$ values indicate differences in the surface roughness for the solids studied, provided the adsorbate used is the same.

If the solids studied are truly non-porous, it is reasonable to assume that multilayer adsorption occurs, and hence that differences in the exponents of eqn. 2 are due to different strengths of interaction between the adsorbate and the solids. However, most solids exhibit some porosity and the traditional attempts to rationalize experimental $s$ values in terms of types of interactions should include geometrical considerations as well (Avnir \& Jaroniec, 1989).

It has been shown that surface fractal dimensions, $D_{\mathrm{s}}$, obtained by fitting $\mathrm{N}_{2}$ adsorption data to eqn. 1 are largely greater for microporous materials than those for non-porous samples (Lefebvre et al., 1992; Celis et al., 1996). However, it seems to be necessary to apply the fractal approach to many other specific problems in order to check the validity and usefulness of the information obtained by applying the fractal approach to nitrogen adsorption data.

In the present paper several techniques have been used to study the changes in porosity of kaolinite and montmorillonite after ferrihydrite association. Special attention has been given to the applicability of the fractal theory to interpret $\mathrm{N}_{2}$ adsorption data (Avnir \& Jaroniec, 1989). The conclusions from assuming a fractal pore-size distribution in the samples were compared with those obtained from classical interpretations of $\mathrm{N}_{2}$ adsorption isotherms.

\section{MATERIALS AND METHODS}

\section{Minerals}

Wyoming montmorillonite, SWy-1, and Georgia kaolinite, KGa-2, were supplied by the Clay Mineral Repository of the Clay Minerals Society.

Ferrihydrite was prepared following the procedure of Russell (1979); a solution of $0.06 \mathrm{M}$ $\mathrm{Fe}\left(\mathrm{NO}_{3}\right)_{3}$ was boiled for $8 \mathrm{~min}$, dialysed until $\mathrm{NO}_{3}^{-}$free, then freeze dried. It was identified by $\mathrm{X}$-ray diffraction (XRD) showing the six diffraction lines corresponding to a well-crystallized ferrihydrite.

\section{Synthesis of clay-ferrihydrite associations}

Kaolinite-ferrihydrite and montmorilloniteferrihydrite associations were prepared by boiling for $8 \mathrm{~min}$ suspensions containing $1.4 \mathrm{~g}$ of clay and $50 \mathrm{ml}$ of $\mathrm{Fe}\left(\mathrm{NO}_{3}\right)_{3} \cdot 9 \mathrm{H}_{2} \mathrm{O}$ with 0 (blank), 7.5, 30, 60 and $120 \mathrm{mg} \mathrm{Fe} / \mathrm{g}$ clay, while constantly stirring. The $\mathrm{pH}$ ranged between 1.5 and 3.2, for the suspensions containing 120 and $7.5 \mathrm{mg} \mathrm{Fe} / \mathrm{g}$ clay, respectively, whereas the $\mathrm{pH}$ of the blank clay suspensions was 7.9 for montmorillonite and 6.1 for kaolinite. A blank sample was also prepared by boiling $1.4 \mathrm{~g}$ of montmorillonite for $8 \mathrm{~min}$ at the same $\mathrm{pH}$ as that of the suspension containing $120 \mathrm{mg} \mathrm{Fe} / \mathrm{g}$ clay (pH 1.5), and it was identified by XRD. All clayferrihydrite associations and blanks were washed until $\mathrm{NO}_{3}^{-}$free, lyophilized and stored at room temperature until used.

\section{Iron content of the associations}

The Fe content in the clay-ferrihydrite associations was determined by oxalate extraction following the procedure of McKeague \& Day (1966): $50 \mathrm{mg}$ of sample were treated with a solution of $10 \mathrm{ml}$ of $0.2 \mathrm{M}$ ammonium oxalate/ oxalic acid, shaken in complete darkness and centrifuged. The $\mathrm{Fe}$ (III) in the supernatant was determined by atomic absorption spectroscopy.

\section{Nitrogen adsorption isotherms}

Nitrogen adsorption-desorption isotherms were obtained using a Carlo Erba Sorptomatic 1900 (Fisons Instr., Milan). Samples were outgassed at $80^{\circ} \mathrm{C}$ and equilibrated under vacuum for $4 \mathrm{~h}$ before measuring the $\mathrm{N}_{2}$ adsorption-desorption isotherms. The BET specific surface areas, $S_{\mathrm{BET}}$, were calculated by applying the BET method (Brunauer et al., 1938) to adsorption data between relative pressures of 0.02 and 0.30 . The t-plots (Lippens \& de Boer, 1965) were obtained using the standard isotherm proposed by Sing and his co-workers (Gregg \& Sing, 1982) from a wide variety of nonporous silicas, and external surface areas, $S_{t}$, were calculated from the slope of the linear region of the t-plots (Lippens \& de Boer, 1965). Surface fractal dimensions (Mandelbrot, 1982) were calculated from adsorption data assuming the Avnir and Jaroniec equation (eqn. 1), which can be rewritten as follows: 


$$
V_{\mathrm{ads}}=\mathrm{K} \cdot\left[\log \left(\frac{p_{1}}{p}\right)\right]^{D_{\mathrm{s}}-3}
$$

where $V_{\text {ads }}$ is the volume of $\mathrm{N}_{2}$ adsorbed at the relative pressure $p / p_{0}, \mathrm{~K}$ is a characteristic constant, and $D_{\mathrm{s}}$ is the fractal dimension of surface accessible to adsorption. The value for $D_{\mathrm{s}}$ can be obtained from the slope of a plot of $\log \left(V_{\text {ads }}\right)$ vs. $\log \log$ $\left(p_{\mathrm{o}} / p\right)$ in the region of low adsorption potentials (Avnir \& Jaroniec, 1989; Yin, 1991; Lefebvre et al., 1992; Celis et al., 1996).

\section{Mercury porosimetry}

The distribution of pore radii of clay-ferrihydrite samples from $4 \times 10^{4}$ to $3.7 \mathrm{~nm}$ was determined using a Carlo Erba 2000 mercury depression and intrusion porosimeter (Fisons Instr., Milan). Samples were previously dried by heating at $90^{\circ} \mathrm{C}$ for $24 \mathrm{~h}$ and then outgassed at room temperature for $30 \mathrm{~min}$. A value for the surface tension of mercury of $0.48 \mathrm{~N} \mathrm{~m}^{-1}$ and a contact angle on solids of $141.3^{\circ}$ were used with the Washburn (1921) equation assuming cylindrical pores in the calculations.

\section{$X$-ray diffraction and electron microscopy}

$\mathrm{X}$-ray diffractograms of the powder samples were obtained with a Siemens D-500 diffractometer (Siemens, Stuttgart) using $\mathrm{Cu}-K \alpha$ radiation. Powder samples were also observed in a JEOL 5400 scanning electron microscope equipped with an X-ray dispersive energy analyser (EDAX).

\section{RESULTS AND DISCUSSION}

\section{Iron content of the associations}

The amounts of $\mathrm{Fe}$ in the clay-ferrihydrite associations were similar for kaolinite and montmorillonite (Table 1). An extraction time of $4 \mathrm{~h}$ (McKeague \& Day, 1966) was long enough for montmorillonite complexes to become colourless, but kaolinite complexes with the greatest amounts of $\mathrm{Fe}$ needed to be shaken for $24 \mathrm{~h}$. A possible explanation for this behaviour is a stronger association of $\mathrm{Fe}$ particles in the presence of kaolinite than in the presence, of montmorillonite after drying. Greater dispersion of the montmorillonite complex particles in the oxalate extracting solution as well as differences in particle size or crystallinity of the $\mathrm{Fe}$ associated in both
TABlE 1. Oxalate extractable $\mathrm{Fe}\left(\mathrm{Fe}_{\mathrm{o}}\right)$ in the clayferrihydrite associations with different initial $\mathrm{Fe}$ contents $\left(\mathrm{Fe}_{\text {ini }}\right)$ measured after $4 \mathrm{~h}$ and $24 \mathrm{~h}$ of extraction time.

\begin{tabular}{ccc}
\hline & \multicolumn{2}{c}{$\mathrm{mg} \mathrm{Fe}_{\mathrm{o}} / \mathrm{g}$ association } \\
mg Fe & Montmorillonite \\
\hline 0 & $0.0^{\mathrm{a}}(0.0)^{\mathrm{b}}$ & $0.9(1.0)$ \\
7.5 & $6.6(7.5)$ & $8.3(7.8)$ \\
30 & $23.5(21.0)$ & $24.9(26.0)$ \\
60 & $40.2(25.6)$ & $40.3(38.8)$ \\
120 & $56.1(21.3)$ & $54.2(53.0)$
\end{tabular}

a Extraction time: $24 \mathrm{~h}$

${ }^{\mathrm{b}}$ Extraction time: $4 \mathrm{~h}$

clays would also lead to differences in oxalate extractability. Pure ferrihydrite was found to need a long term $(24 \mathrm{~h})$ oxalate treatment in order to be completely dissolved, probably due to lower oxalate/Fe ratio as a result of high $\mathrm{Fe}$ content in pure ferrihydrite.

\section{$X$-ray diffraction}

$\mathrm{X}$-ray examination of the complexes revealed no diffraction lines corresponding to 6-line ferrihydrite or other crystalline forms of Fe oxides. This can be due not only to small amounts of $\mathrm{Fe}$ in the complexes $(<15 \%)$ but also to the presence of clay minerals which can have a strong influence on $\mathrm{Fe}$ oxide formation (Schwertmann, 1979, 1988). Since clays hinder crystallization, it is very likely that the presence of clay has inhibited the growth of crystalline 6-line ferrihydrite, particularly under the influence of low $\mathrm{pH}$ during the synthesis of the clay-ferrihydrite complexes (Schwertmann, 1979). Silicon and $\mathrm{Al}$ from the clays may have gone into solution inhibiting crystal growth, lowering crystal order or inducing formation of $\mathrm{Al}$-substituted ferrihydrite, which is usually of poorer crystallinity than ferrihydrite formed in the absence of $\mathrm{Al}$ (Schwertmann, 1988). Phyllosilicates usually mask the characteristic broad peaks of these poorlyordered materials, especially when small amounts of $\mathrm{Fe}$ are present

The position $(0.72 \mathrm{~nm})$ of the original first-order basal diffraction line of kaolinite was not affected by ferrihydrite association. However, its intensity decreased slightly with the amount of ferrihydrite (Fig. 1). In contrast, a great decrease and broad- 


\section{Kaolinite}

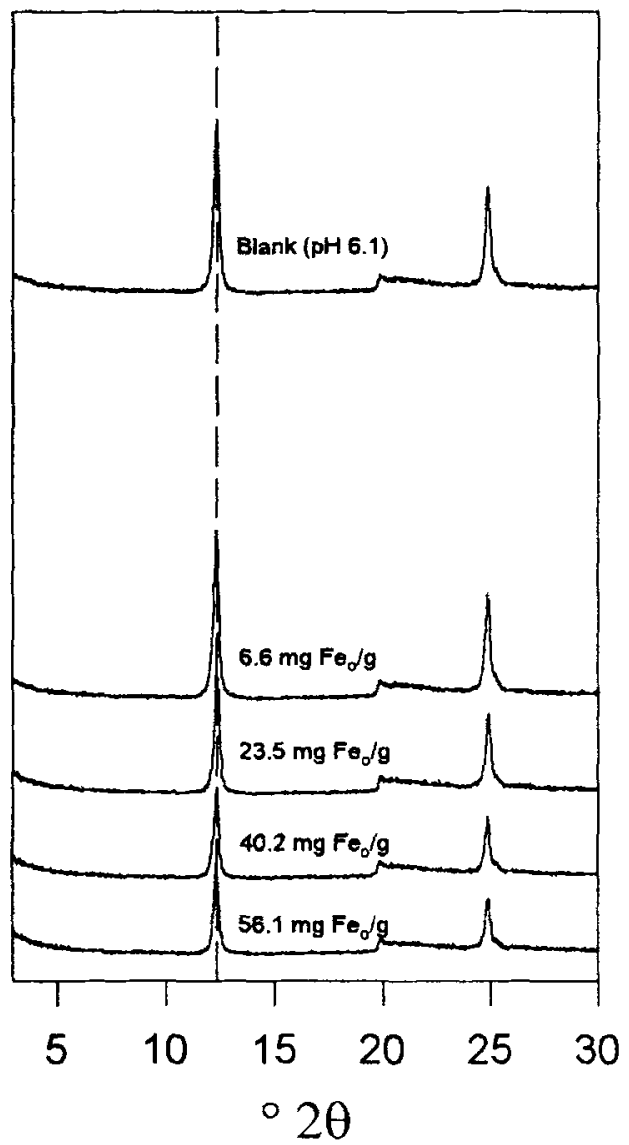

Montmorillonite

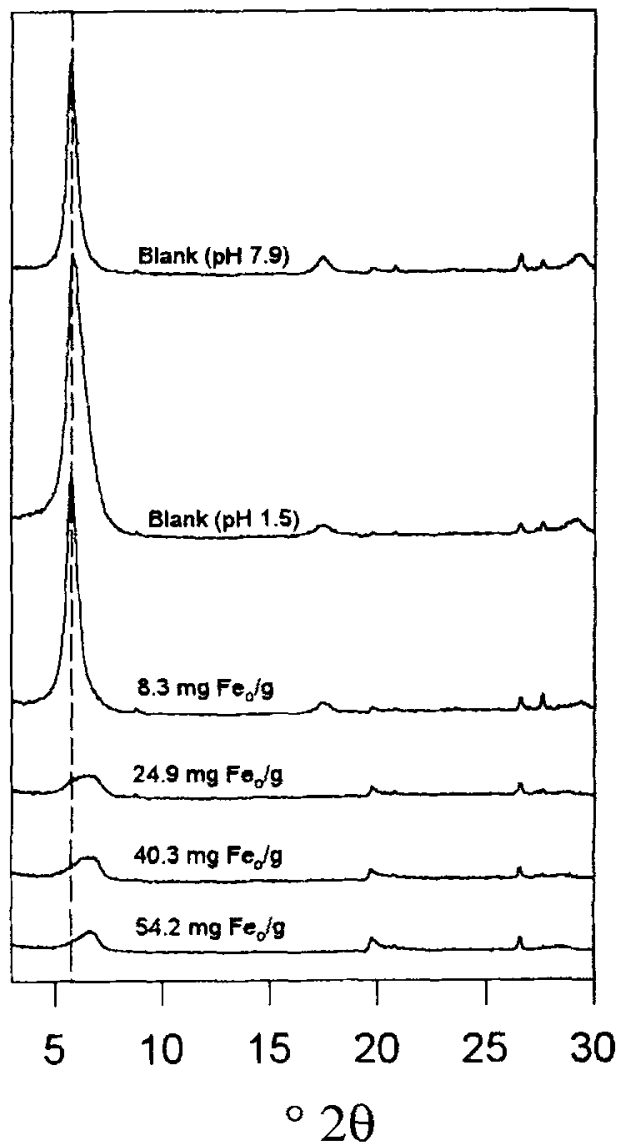

Fig. 1. X-ray diffraction patterns of $001 d$-spacings of clay-ferrihydrite associations.

ening of this diffraction line was observed for montmorillonite associated with greater amounts of $\mathrm{Fe}$ (Fig. 1). Since the association of ferrihydrite may be influenced by the cation exchange capacity (CEC) of phyllosilicates, the Fe oxide particles may be held on the negatively charged basal surfaces of clays, then more on montmorillonite than on kaolinite. The ferrihydrite association with the negatively charged basal surfaces should make the orientation of the montmorillonite quasi-crystals more difficult during sample drying, resulting in broadening of the basal diffraction. A similar decrease in the intensity (but not the position) of the $d_{001}$ lines in the X-ray diffractogram of montmorillonite by humic acid association was reported by Varadachari et al. (1991) and attributed to humic acid interaction with the basal surfaces of the clay, causing disruption in the stacking of the montmorillonite layers during drying. Although basal spacing values, showing a collapse to $1.0 \mathrm{~nm}$ after heating at $200^{\circ} \mathrm{C}$ (not shown), did not indicate that ferrihydrite was interlayered in the complexes (Barnhisel \& Bertsch, 1989), the shift of the $001 d$-spacing of montmorillonite to higher angles (lower spacings) observed in Fig. 1 may suggest partial substitution of the original interlayer cations and their water molecules by less hydrated $\mathrm{Fe}^{3+}$ monorners or very small poly-[Fe(III)-OH] cations during the synthesis of the complexes. The $\mathrm{pH}$ effects can be rejected since a blank sample prepared by keeping montmorillonite for $8 \mathrm{~min}$ at $100^{\circ} \mathrm{C}$ at the same $\mathrm{pH}$ as that of the complex containing $120 \mathrm{mg} \mathrm{Fe} / \mathrm{g}$ montmorillonite $(\mathrm{pH} 1.5$ ) resulted in the same basal spacing as that of the blank sample prepared at higher $\mathrm{pH}$ (Fig. 1). All these changes in the XRD patterns of the mont- 
morillonite-ferrihydrite associations are not observed in kaolinite because its low CEC, relatively coarse particle size, and lack of swelling should reduce considerably the negatively charged basal surface exposed in solution for Fe association.

\section{Nitrogen adsorption isotherms}

Nitrogen adsorption-desorption isotherms for kaolinite-ferrihydrite and montmorilionite-ferrihydrite associations are shown in Fig. 2. Adsorption isotherms on kaolinite were of type II, according to the Brunauer et al. (1940) classification, and were characterized by the absence of an hysteresis loop. This agrees with the presence of large pores (macropores) resulting from the arrangement of the coarse kaolinite particles by drying (Murray \& Quirk, 1990; Celis et al., 1996). Little change in the shape of the isotherm was observed after ferrihydrite association with kaolinite. The $\mathrm{N}_{2}$ adsorption isotherm on montmorillonite was similar to those reported by other authors (Brooks, 1955; Aylmore \& Quirk, 1967; Celis et al., 1996). It was of type IV with an hysteresis loop of type H3 (IUPAC, 1985), which agrees with small slit-shaped pores resulting from the arrangement of the thin platelets of montmorillonite during drying (Gregg \& Sing, 1982). Adsorption isotherms on montmorilloniteferrihydrite complexes with small amounts of $\mathrm{Fe}$ were similar to that on pure montmorillonite (with a greater degree of hysteresis in the case of the complex with $24.9 \mathrm{mg} \mathrm{Fe}_{\mathrm{o}} / \mathrm{g}$ ); however, those for the complexes with the two greatest amounts of $\mathrm{Fe}$ showed a great reduction in hysteresis, thus suggesting a significant reduction in fine pores.

The $\mathrm{N}_{2}$ specific surface area of montmorillonite is strongly dependent on the water content of the sample during the $\mathrm{N}_{2}$ adsorption experiment (Brooks, 1955). The weight losses measured for the montmorillonite-ferrihydrite associations, shown in Table 2, are in agreement with the values reported by Brooks (1955) for Na-Wyoming bentonite which has lost all the water of adsorption and hydration to leave $\sim 5 \%$ water of constitution as an integral part of the clay structure. These weight losses $(\sim 10 \%)$ are nearly the same for the different montmorillonite-ferrihydrite associations studied, so we can compare the values of $S_{\mathrm{BET}}$ obtained for the different samples. The $\mathrm{N}_{2}$ surface area of kaolinite is not strongly dependent on the loss of water of adsorption or hydration (Brooks, 1955). As shown in Table 2, the water losses by outgassing kaoliniteferrihydrite associations are much less than those for montmorillonite.

The low value of the specific surface area $\left(11 \mathrm{~m}^{2} / \mathrm{g}\right)$ measured for montmorillonite without ferrihydrite (blank) compared to that for the crude clay $\left(24.9 \mathrm{~m}^{2} / \mathrm{g}\right)$ can be explained if we take into account that the sample treatment previous to obtaining the adsorption isotherm has a strong influence on the sedimentation of montmorillonite quasi-crystals and, therefore, on the pore matrix after sample drying. Regular stacking of montmorilionite lamellae during drying reduces porosity thus resulting in low specific surface area (Srasra $e t$ al., 1989; Van Damme \& Ben Ohoud, 1990). Thus, by careful preparation of oriented flakes, GreeneKelly (1964) reduced the $\mathrm{N}_{2}$ specific surface area of $\mathrm{Na}$-Wyoming bentonite to some $5 \mathrm{~m}^{2} / \mathrm{g}$ compared with the $40-50 \mathrm{~m}^{2} / \mathrm{g}$ frequently obtained for this clay. Kaolinite was unaffected by the blank treatment, since the value of $18.4 \mathrm{~m}^{2} / \mathrm{g}$ for $S_{\mathrm{BET}}$ of kaolinite without ferrihydrite (blank) is close to that of $20.1 \mathrm{~m}^{2} / \mathrm{g}$ corresponding to the crude kaolinite sample.

The BET specific surface areas, $S_{\mathrm{BET}}$, of kaolinite- and montmorillonite-ferrihydrite associations increased with the amounts of ferrihydrite in the

TABLE 2. Weight loss and specific surface areas, $S_{\mathrm{BET}}$ and $S_{\mathrm{t}}$, for clay-ferrihydrite associations.

\begin{tabular}{|c|c|c|c|c|c|c|c|c|c|}
\hline \multirow{3}{*}{$\frac{\begin{array}{c}\mathrm{Fe}_{\mathrm{o}} \\
(\mathrm{mg} / \mathrm{g})\end{array}}{0.0}$} & \multicolumn{3}{|c|}{ Kaolinite associations } & \multicolumn{6}{|c|}{ Montmorillonite associations } \\
\hline & $\begin{array}{l}\text { weight loss } \\
(\%)\end{array}$ & $S_{\mathrm{BET}}$ & $S_{1}$ & $\begin{array}{c}\mathrm{Fe}_{\mathrm{o}} \\
(\mathrm{mg} / \mathrm{g})\end{array}$ & $\begin{array}{l}\text { weight loss } \\
(\%)\end{array}$ & $S_{\mathrm{BET}}$ & $S_{\mathrm{t}}\left(\mathrm{m}^{2} /\right.$ & $S_{\mathrm{ext}}$ & $S_{\mathrm{mp}}$ \\
\hline & 0.6 & 18.4 & 18.0 & 1.0 & 10.0 & 11.0 & 10.6 & - & - \\
\hline 6.6 & 0.6 & 22.1 & 21.6 & 8.3 & 13.0 & 37.4 & 38.6 & 27.8 & 9.6 \\
\hline 23.5 & 1.4 & 28.1 & 27.7 & 24.9 & 8.8 & 50.0 & 51.3 & 32.6 & 17.4 \\
\hline 40.2 & 1.5 & 31.1 & 31.6 & 40.3 & 9.0 & 54.5 & 55.5 & - & - \\
\hline 56.1 & 1.4 & 34.0 & 34.0 & 54.2 & 8.8 & 62.1 & 63.2 & - & - \\
\hline
\end{tabular}



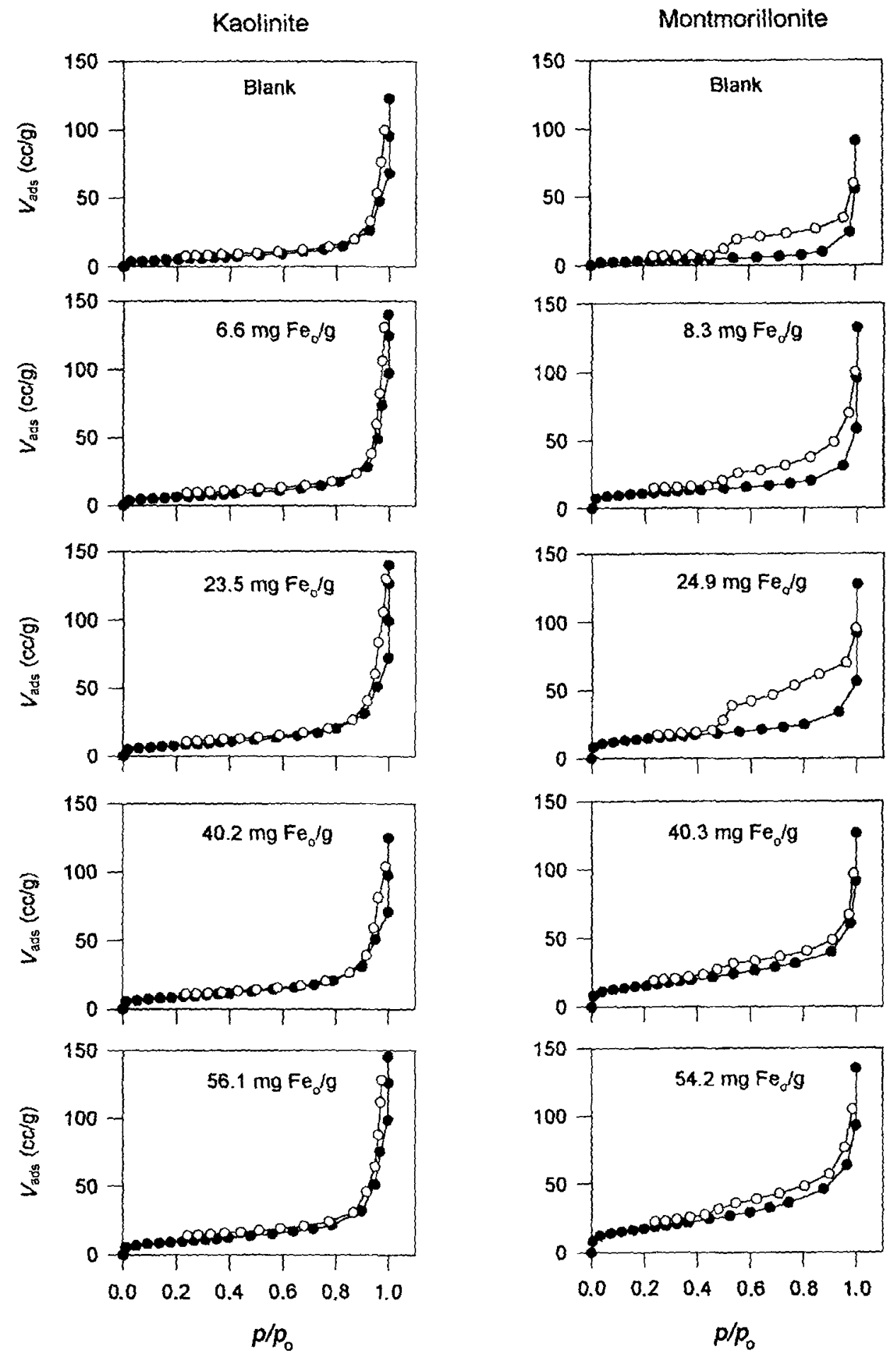

FIG. 2, Nitrogen adsorption-desorption isotherms on clay-ferrihydrite associations. 
samples; however, the increase was greater for montmorillonite (Table 2). If we assume clayferrihydrite associations to be mechanical mixtures of the two components, the total surface area would be given by the addition of the surface areas of the amount of each component, i.e.

$$
S_{\mathrm{m}}=S_{\mathrm{c}}(1-\theta)+S_{\mathrm{r}} \theta
$$

where $S_{\mathrm{m}}$ is the total specific surface area for the mixture, $S_{\mathrm{c}}$ and $S_{\mathrm{f}}$ are the specific surface area for the clay and ferrihydrite samples, respectively, and $\theta$ is the proportion of ferrihydrite in the mixture. Pure ferrihydrite, prepared as a reference, had $S_{\mathrm{BET}}=152 \mathrm{~m}^{2} / \mathrm{g}$ and its weight loss on outgassing was $7.3 \%$. Although the amount of ferrihydrite in the samples cannot be measured directly, assuming the structural formula $\mathrm{Fe}_{2} \mathrm{O}_{3} \cdot 2 \mathrm{FeOOH} \cdot 2.6 \mathrm{H}_{2} \mathrm{O}$ proposed by Russell (1979) from infrared spectroscopy, the Fe content in ferribydrite is nearly $60 \%$. Thus we can estimate the $S_{\mathrm{BET}}$ of the complexes as a function of the $\mathrm{Fe}$ content and assuming heterogeneous mixtures of clay and pure ferrihydrite. As can be seen in Fig. 3, experimental $S_{\mathrm{BET}}$ values for the kaolinite-ferrihydrite complexes fitted reasonably well to the model of non-interaction between the individual components. On the contrary, the experimental values of $S_{\mathrm{BET}}$ for the montmorillonite complexes were much greater than those expected for heterogeneous mixtures of

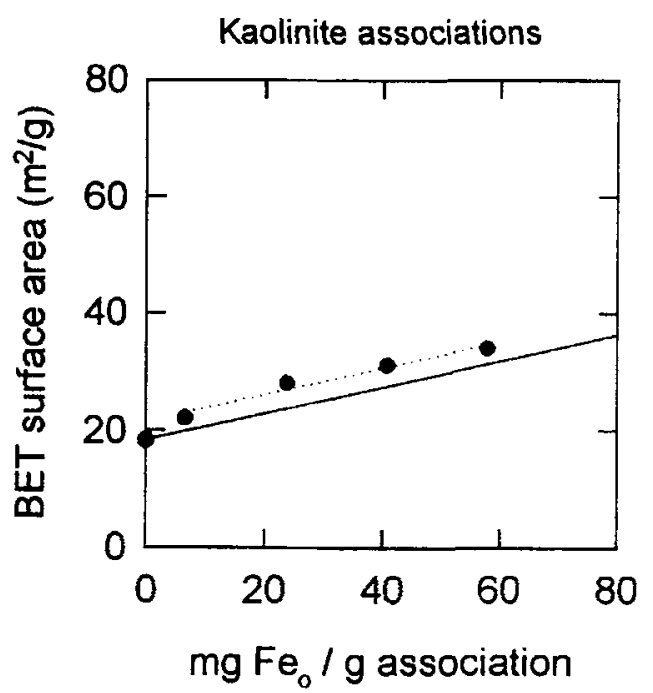

montmorillonite and ferrihydrite. Although the pronounced difference of $S_{\mathrm{BET}}$ for the untreated and subsequent data could be due to preparation effects of the blank sample, it should be noted that the increase in $S_{\mathrm{BET}}$ for montmorillonite is linear for $\mathrm{Fe}$ contents $\geqslant 8.3 \mathrm{mg} / \mathrm{g}$ and the observed slope is still larger than calculated for the mixture of pure ferrihydrite and montmorillonite (Fig. 3). This discrepancy could mean that the composition or surface morphology of the Fe phase formed in the presence of montmorillonite is different (higher surface area) from the pure ferrihydrite whereas kaolinite did not influence ferrihydrite formation. In fact, smectites have been shown to retard $\mathrm{Fe}$ oxide crystallization to a greater extent than kaolinite (Schwertmann, 1979). Moreover, as mentioned above, the $\mathrm{Fe}$ oxide particles may be held on the negatively charged basal surfaces of clays, more on montmorillonite than on kaolinite, making the orientation of the montmorillonite flakes more difficult during sample drying, thus increasing porosity and the specific surface area of the resulting clay-ferrihydrite complexes.

The t-plots (Lippens \& de Boer, 1965) of the $\mathrm{N}_{2}$ adsorption data for all kaolinite-ferrihydrite complexes were typical of mesoporous materials (Fig. 4). They showed a first linear region corresponding to multilayer adsorption on a relatively smooth surface followed by a significant

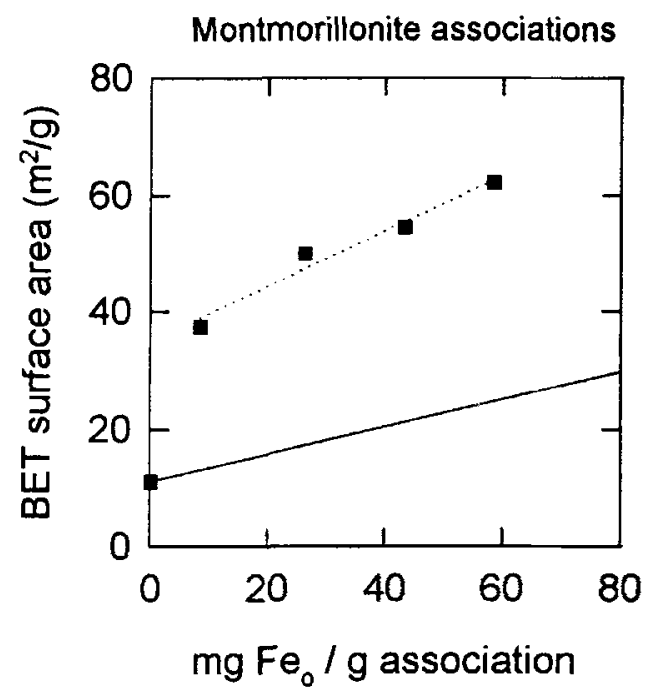

FIG. 3. Values of $S_{\mathrm{BET}}$ for the clay-ferrihydrite associations as a function of the Fe content. The Symbols correspond to experimental values whereas solid lines correspond to values calculated assuming mechanical mixtures of clay and ferrihydrite. 

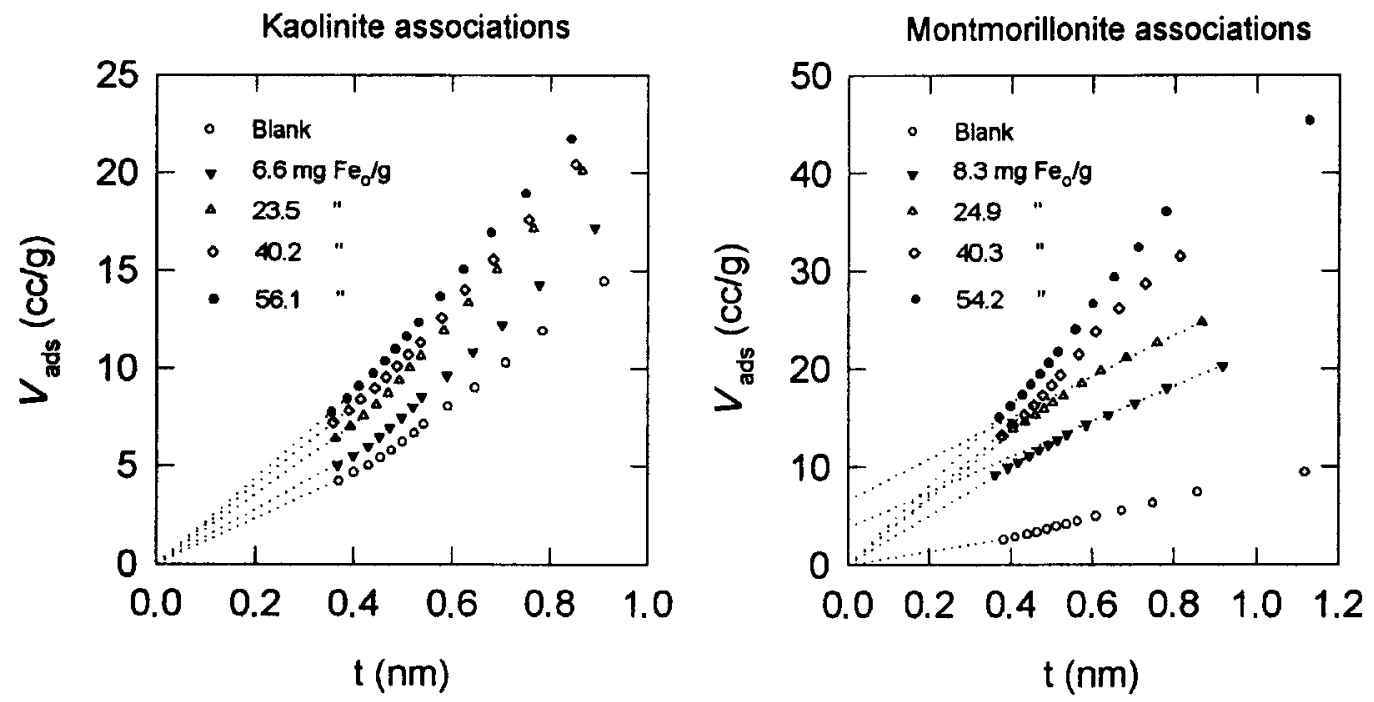

FIG. 4. t-plots of clay-ferrihydrite associations.

increase in the $\mathrm{N}_{2}$ uptake when capillary condensation began in the mesopores of the sample (Gregg $\&$ Sing, 1982). The surface areas derived from the slope of the initial linear region of the t-plots, $S_{\mathrm{t}}$, were in good agreement with the corresponding $S_{\text {BET }}$ (Table 2). The $S_{1}$ values were always slightly $>S_{\mathrm{BET}}$, which has no physical meaning and can be attributed to slight differences between the nature of the surfaces considered and that of the standard used (Gregg \& Sing, 1982). The t-plots for montmorillonite-ferrihydrite complexes were dependent on the amounts of ferrihydrite. the t-curves for the complexes with the two lowest doses of $\mathrm{Fe}$ showed downward deviations indicative of microporosity (Sing, 1967). For such microporous samples, both the total area, $S_{\mathrm{l}}$, and the external area, $S_{\text {ex }}$, are calculated from the slopes of the initial steep line and the less steep line after the intersection in the t-plots, respectively. The difference between $S_{\mathrm{BET}}$ and $S_{\mathrm{cx}}$ may be assumed as micropore surface, $S_{\mathrm{mp}}$. The surface area due to micropores $\left(S_{\mathrm{BET}}-S_{\mathrm{cx}}\right)$ were $9.6 \mathrm{~m}^{2} / \mathrm{g}$ for the complex with $8.3 \mathrm{mg} \mathrm{Fe} / \mathrm{g}$ and $17.4 \mathrm{~m}^{2} / \mathrm{g}$ for the complex with $24.9 \mathrm{mg} \mathrm{Fe}_{\mathrm{o}} / \mathrm{g}$. The micropore volumes, $V_{\mathrm{mp}}$, obtained from the intercept of the first linear region of the t-plots (Fig. 4) were $0.00603 \mathrm{cc} / \mathrm{g}$ for the complex with $8.3 \mathrm{mg} \mathrm{Fe} / \mathrm{g}$ and $0.0103 \mathrm{cc} / \mathrm{g}$ for the complex with $24.9 \mathrm{mg} \mathrm{Fe} / \mathrm{g}$. In contrast, t-curves for the complexes with the two highest doses of Fe were typical of mesoporous materials, with $S_{1}$ quite similar to $S_{\mathrm{BET}}$, thus resembling those of the kaolinite complexes.

Fractal analysis. Nitrogen adsorption isotherms on the different clay-ferrihydrite associations plotted according to the logarithmic plot of the Avnir \& Jaroniec equation (eqn. 3) are shown in Fig. 5. Two regions of linearity were found (above and below $p / p_{\mathrm{o}}=0.5$ ). The resulting surface fractal dimensions for each region are shown in Table 3. Although it is not intuitively evident which of the adsorption data ranges best relates to the fractal dimension of the surface, in our case, the changes in $D_{\mathrm{s}}$ values of the associations with increasing amounts of ferrihydrite followed the same tendency for both relative pressure ranges. Most of $D_{\mathrm{s}}$ values in Table 3 are in the range of 2.5-2.75, reported by Lefebvre et al. (1992) for a number of widely different samples; however, the changes in $D_{\mathrm{s}}$ values with increasing amounts of ferrihydrite in the montmorillonite associations were quite different from those in the case of kaolinite. Thus, for the two regions, $D_{\mathrm{s}}$ values for the kaolinite associations were low and showed only a small increase with increasing amounts of ferrihydrite (Table 3). In contrast, large $D_{\mathrm{s}}$ values were found for the associations with the smallest amounts of ferrihydrite whereas small $D_{\mathrm{s}}$ values were found for the associations with the largest amounts of ferrihydrite.

The low $D_{\mathrm{s}}$ values shown in Table 3 for the kaolinite-ferrihydrite associations are consistent 
Kaolinite associations

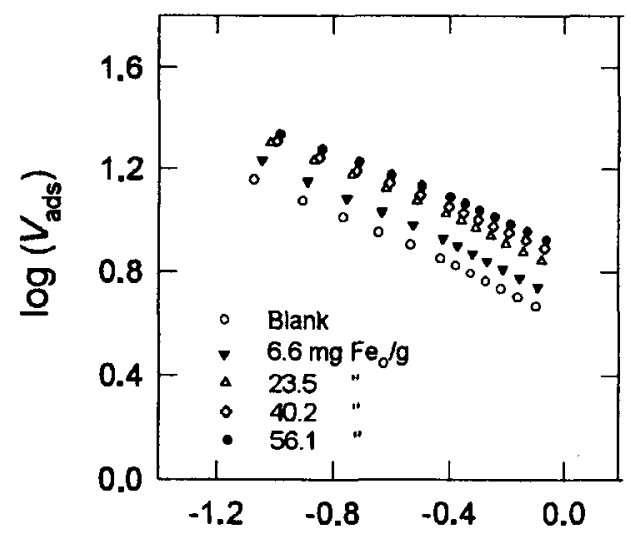

$\log \log \left(p_{0} / p\right)$
Montmorillonite associations

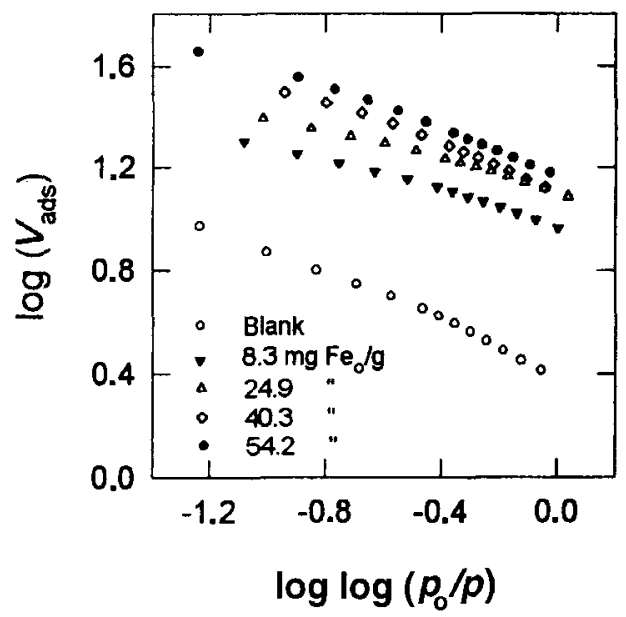

FIG. 5. Nitrogen adsorption isotherms for the clay-ferrihydrite associations plotted according to the Avnir and Jaroniec equation.

with those for meso- or macroporous materials, the slight increase in $D_{\mathrm{s}}$ for the samples with the greatest amounts of ferrihydrite being related to a relatively small increase in the surface roughness. For montmorillonite, the $D_{\mathrm{s}}$ values reported in Table 3 indicated that, whereas the increases in the specific surface areas of the associations with the smallest amounts of ferrihydrite are due to the presence of micropores, in the case of the complexes with the greatest amounts of ferrihydrite the absence of micropores could be indicated by the decrease in the surface fractal dimension calculated for these samples. It is worthwhile to note that these conclusions agree with those obtained from the t-analysis of the adsorption isotherms (Fig. 4) in which the presence of mesoporosity was apparent for the montmorillonite complexes with the greatest amounts of ferrihydrite as well as for all kaolinite associations.

The presence of greater mesoporosity and the absence of microporosity in the montmorillonite complexes with greater amounts of $\mathrm{Fe}(40.3$ and $54.2 \mathrm{mg} \mathrm{Fe} / \mathrm{g}$ complex) directly indicated by t-plots and indirectly by $D_{\mathrm{s}}$ values, could be related to the fact that concentrated solutions of $\mathrm{Fe}^{3+}$ give rise to the formation of $\mathrm{Fe}$ polymers larger than those formed from diluted solutions (Rengasamy \& Oades, 1977a). If so, the separation between quasi-crystals in montmorillonite after drying as well as the interaggregate space of $\mathrm{Fe}$ particles themselves (Fusi et al., 1993) would be even larger and might fall in the pore-size range of mesopores.

TABLE 3. Surface fractal dimensions, $D_{s}$, for the clay-ferrihydrite associations calculated by applying the Avnir \& Jaroniec (1989) equation 1 to $\mathrm{N}_{2}$ adsorption data. Standard errors of the calculated $D_{s}$ values were $\leqslant 0.01$ in all cases.

\begin{tabular}{lccccc}
\hline & Kaolinite associations & \multicolumn{2}{c}{ Montmorillonite associations } \\
$\left(\begin{array}{c}\mathrm{Fe}_{\mathrm{o}} \\
\left(\mathrm{mg} \mathrm{g}^{-1}\right)\end{array}\right.$ & $\begin{array}{c}D_{\mathrm{s}} \\
\left(p / p_{\mathrm{o}}<0.5\right)\end{array}$ & $\begin{array}{c}D_{\mathrm{s}} \\
\left(p / p_{\mathrm{o}}>0.5\right)\end{array}$ & $\begin{array}{c}\mathrm{Fe}_{\mathrm{o}} \\
\left(\mathrm{mg} \mathrm{g}^{-1}\right)\end{array}$ & $\begin{array}{c}D_{\mathrm{s}} \\
\left(p / p_{\mathrm{o}}<0.5\right)\end{array}$ & $\begin{array}{c}D_{\mathrm{s}} \\
\left(p / p_{\mathrm{o}}>0.5\right)\end{array}$ \\
\hline 0.0 & 2.44 & 2.53 & 1.0 & 2.41 & 2.59 \\
6.6 & 2.44 & 2.52 & 8.3 & 2.62 & 2.73 \\
23.5 & 2.46 & 2.55 & 24.9 & 2.65 & 2.75 \\
40.2 & 2.53 & 2.58 & 40.3 & 2.51 & 2.63 \\
56.1 & 2.51 & 2.58 & 54.2 & 2.52 & 2.65 \\
\hline
\end{tabular}


It is worth noting in this regard that the amounts of $\mathrm{Fe}$ in these complexes were significantly lower than the amounts of $\mathrm{Fe}$ initially added to the clay suspension, the rest being lost during washing (Table 1). This could indicate that the external surface of montmorillonite has been completely covered by $\mathrm{Fe}$ oxide and perhaps inversion of the surface charge of the clay has taken place. Charge reversal has been reported by other authors to cause changes in flocculation, aggregation, particle size and other properties of $\mathrm{Fe}$ and $\mathrm{Al}$ oxide coated clays (Rengasamy \& Oades, 1977b; Oades, 1984; Arias et al., 1995).

\section{Mercury porosimetry and electron microscopy}

Figure 6 shows the evolution of the mercury pore volume of radii smaller and larger than $10 \mu \mathrm{m}$ with increasing amounts of $\mathrm{Fe}$ present in the clayferrihydrite complexes. Ferrihydrite association with kaolinite and montmorillonite led to a decrease in the volume of pores $>10 \mu \mathrm{m}$. The volume of pores $<10 \mu \mathrm{m}$ increased slightly for kaolinite, but in the case of montmorillonite it appears that the two greatest amounts of $\mathrm{Fe}$ lead to an increase in the volume of pores $<10 \mu \mathrm{m}$. This agrees with the characteristic texture (low microporosity and high mesoporosity) of these complexes observed by $\mathrm{N}_{2}$ adsorption isotherms.

Scanning electron microscopy studies corroborated the results obtained by mercury porosimetry. The open lamellar morphology of montmorillonite can be seen in Fig. 7a. In contrast, Fig. $7 b$ and c show the more compact appearance of the montmorillonite complexes with the greater amounts of ferrihydrite. In these samples, it is clear that the effect of ferrihydrite has been to fill the pores partially thereby reducing the macroporosity of the montmorillonite sample. Analysis by EDAX indicated that the distribution of $\mathrm{Fe}$ in the associations is quite homogeneous. No regions with preferential accumulations of $\mathrm{Fe}$ were found on the clay surface.

In summary, ferrihydrite association with montmorillonite and kaolinite results in aggregates with different textures depending on the clay. Isolated ferrihydrite particles seems to bind only to the external surface of the domains (Aylmore \& Quirk, 1967) of kaolinite reducing the volume of largest pores $(>10 \mu \mathrm{m})$ and slightly increasing the specific surface area of the clay. In contrast, ferrihydrite association with montmorillonite causes the pore matrix which results from drying to be very different from that of the clay without ferrihydrite. Different textures were observed for different $\mathrm{Fe}$ loadings in montmorillonite. Although ferrihydrite was not interlayered in the complexes, it appears that $\mathrm{Fe}$ particles, probably of poorer crystallinity than pure ferrihydrite due to Al substitution, disrupt the stacking of the montmorillonite quasicrystals, as depicted in Fig. 8, which may contribute to the large values of specific surface area measured for the resultant associations. The scheme in Fig. 8 is only a simplification since, as reported by other authors, thin lamellae of montmorillonite are

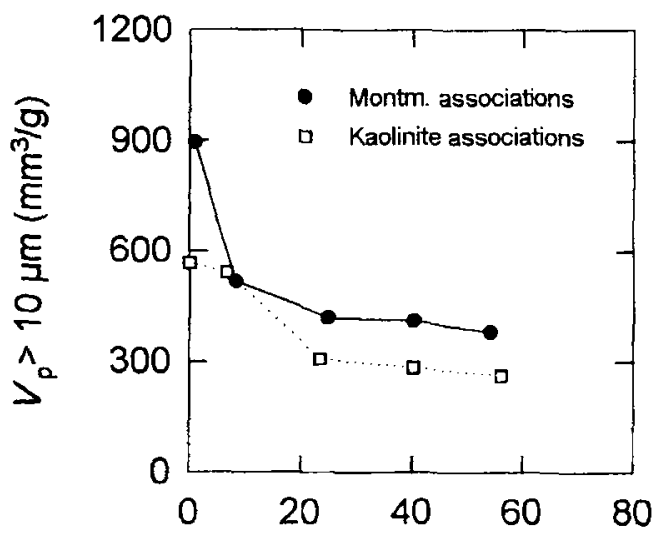

$\mathrm{mg} \mathrm{Fe} / \mathrm{g}$ association

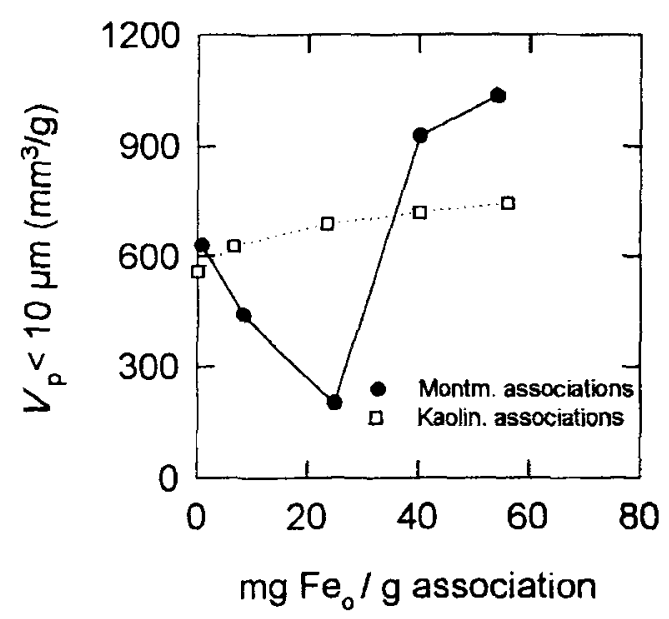

FIG. 6. Mercury pore volume for pore radii smaller and larger than $10 \mu \mathrm{m}$ for the different clay-ferrihydrite associations. 
a

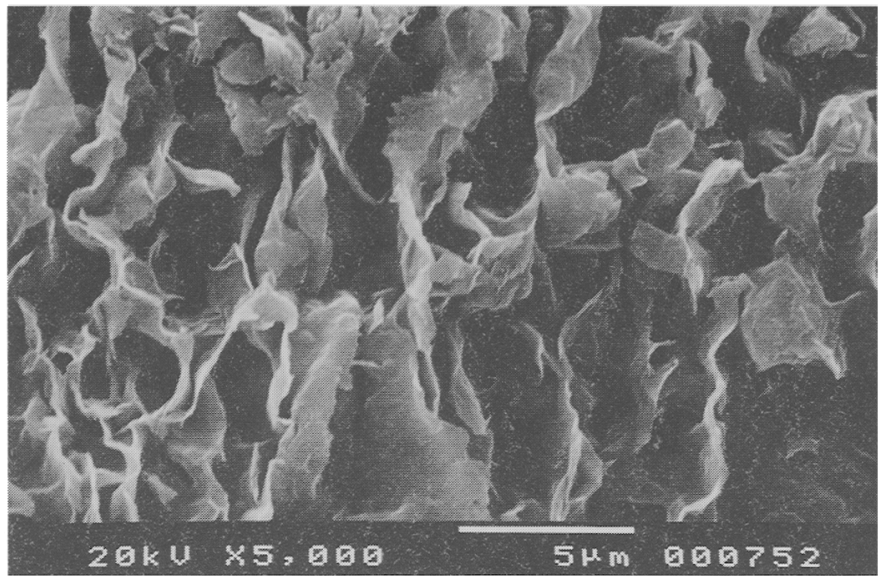

b

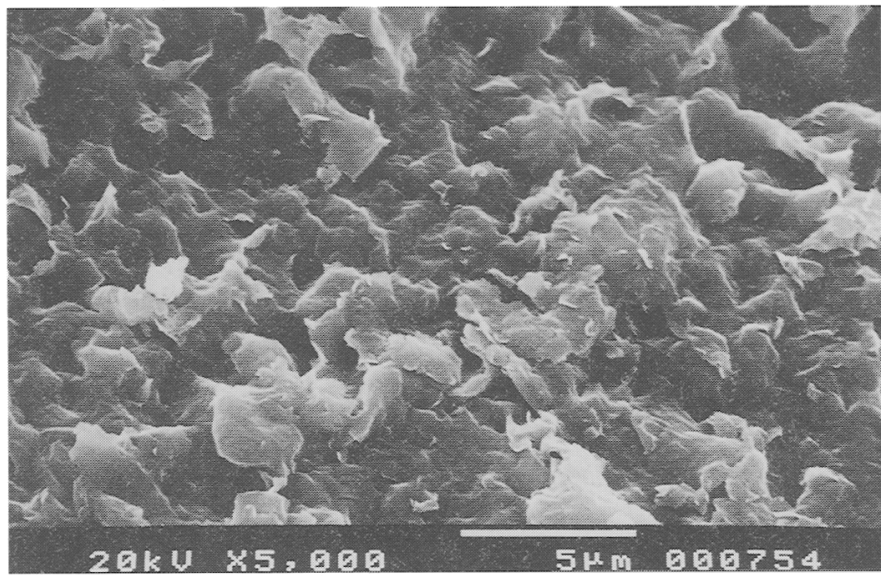

C

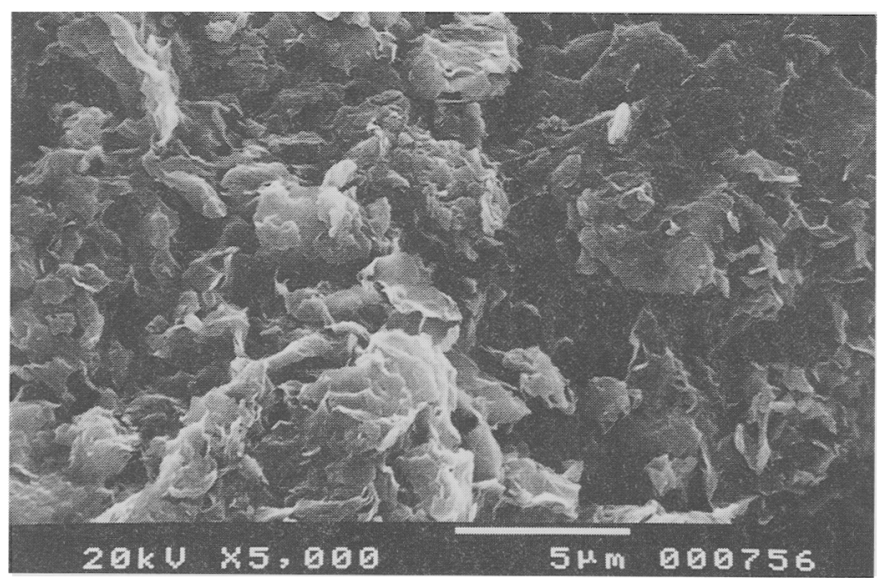

FIG. 7. Scanning electron micrographs of montmorillonite-ferrihydrite associations. (a) $0 \mathrm{mg} \mathrm{Fe} / \mathrm{g}$ (blank), (b) $24.9 \mathrm{mg} \mathrm{Fe} / \mathrm{g}$, (c) $54.2 \mathrm{mg} \mathrm{Fe} / \mathrm{g}$. 


\section{$0 \mathrm{mg} \mathrm{Fe} / \mathrm{g}$}

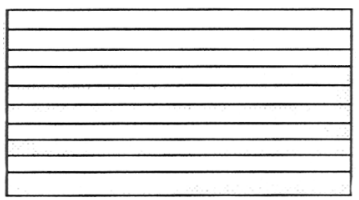

$24.9 \mathrm{mg} \mathrm{Fe} / \mathrm{g}$

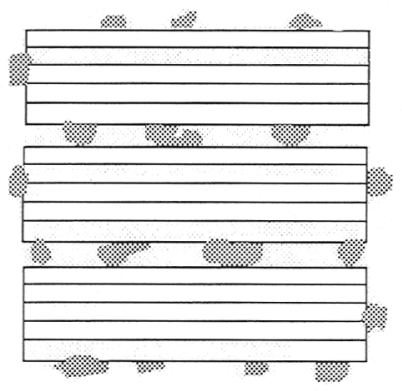

$54.2 \mathrm{mg} \mathrm{Fe} / \mathrm{g}$

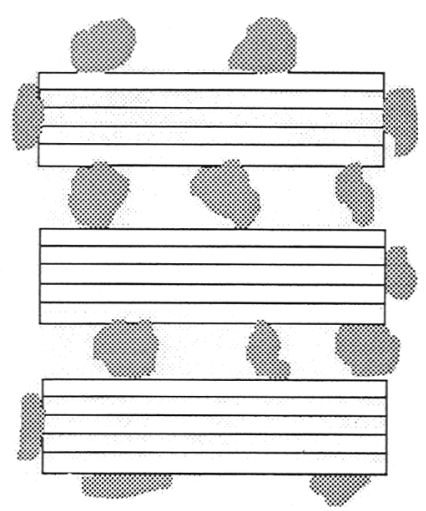

FIG. 8. Scheme of the arrangement of quasi-crystals in montmorillonite-ferrihydrite associations after drying.

subjected to large forces during drying and such forces are responsible for the massive deformation of the thin lamellae, evident in electron micrographs (Fig. 7a), leading to prevalence of cuneiform voids within the remaining microporosity (Greene, 1975; Murray \& Quirk, 1990).

\section{CONCLUSIONS}

The textural properties of kaolinite show little change in association with ferrihydrite. The specific surface areas of kaolinite-ferrihydrite complexes were in agreement with values which correspond to a mixture of both components. Surface fractal dimensions, $D_{\mathrm{s}}$, obtained from the $\mathrm{N}_{2}$ adsorption isotherms following the Avnir \& Jaroniec (1989) equation indicated only a small increase in surface roughness for the associations with the greatest amounts of Fe. The macropore volumes obtained by mercury porosimetry also showed small insignificant differences in kaolinite macroporosity by $\mathrm{Fe}$ association. The position of the original XRD basal spacing was also unaffected by the presence of ferrihydrite. A slight decrease in intensity was observed.

The ferrihydrite association with montmorillonite leads to important changes in the textural properties of the clay. Iron particles may be held on the negatively charged surfaces of montmorillonite, probably with poorer crystallinity than pure ferrihydrite and making the orientation of montmorillonite quasi-crystals more difficult during sample drying, thus resulting in high specific surface areas of the resultant aggregates. Greater loadings of $\mathrm{Fe}$ on montmorillonite make the texture of the complexes significantly different (low microporosity and high mesoporosity) from that of montmorillonite-ferrihydrite complexes with low amounts of Fe.

\section{ACKNOWLEDGMENTS}

This study has been supported partially by the CICYT through the project AMB-93-81, AMB-96-445-CO2$\mathrm{O} 2$, the EU project EV 5V-CT $94-0470$, and by the Research Group RNM 124 of Junta de Andalucía. The authors are grateful to Prof. U. Schwertmann, Dr. P. Weidler, and an anonymous referee for valuable suggestions in their review of the manuscript. $R$. Celis also thanks the Spanish Ministry of Education and Science for his PFPU fellowship.

\section{REFERENCES}

Arias M., Barral M.T. \& Díaz-Fierros F. (1995) Effects of iron and aluminium oxides on the colloidal and surface properties of kaolin. Clays Clay Miner. 43, 406-416.

Avnir D. \& Jaroniec M. (1989) An isotherm equation for adsorption on fractal surfaces of heterogeneous porous materials. Langmuir, 5, 1431-1433.

Aylmore L.A.G. \& Quirk J.P. (1967) The micropore size distribution of clay mineral systems. Soil Sci. 18, $1-17$.

Aylmore L.A.G., Sills I.D. \& Quirk J.P. (1970) Surface 
area of homoionic illite and montmorillonite clay minerals as measured by the sorption of nitrogen and carbon dioxide. Clays Clay Miner. 18, 91-96.

Barnhisel R.I. \& Bertsch P.M. (1989) Chlorites and hydroxyinterlayered vermiculite and smectites. Pp. 729-788 in: Minerals in Soil Environments (J.B. Dixon \& S.S. Weed, editors) SSSA, Madison, WI.

Brooks C.S. (1955) Nitrogen adsorption experiments on several clay minerals. Soil Sci. 79, 331-347.

Brunauer S., Deming L.S., Deming W.S. \& Teller E. (1940) On a theory of the van der Waals adsorption of gases. J. Am. Chem. Soc. 62, 1723-1732.

Brunauer S., Emmett P.H. \& Teller E. (1938) Adsorption of gases in multimolecular layers. $J$. Am. Chem. Soc. 60, 309-319.

Celis R., Cornejo J. \& Hermosin M.C. (1996) Surface fractal dimensions of synthetic clay-hydrous iron oxide associations from nitrogen adsorption isotherms and mercury porosimetry. Clay Miner. 31, $355-363$.

Fusi P., Arfaioli P., Calamai L. \& Bosetto M. (1993) Interactions of two acetanilide herbicides with clay surfaces modified with $\mathrm{Fe}($ III) oxyhydroxides and hexadecyltrimethyl ammonium. Chemosphere, 27 , $764-771$.

Greene R.S.B. (1975) Clay particle assemblage and their interaction with stabilizing agents. $\mathrm{PhD}$ thesis, Univ. Western Australia.

Greene-Kelly R. (1964) The specific surface areas of montmorillonite. Clay Miner. Bull. 5, 392-400.

Gregg S.J. \& Sing K.S.W. (1982) Adsorption, Surface Area and Porosity. 2nd ed. Academic Press. London.

Halsey G.D. (1948) Physical adsorption on non-uniform surfaces. J. Chem. Phys. 16, 931-937.

IUPAC (1985) Reporting physisorption data for gas/ solid systems ith special refernce to the determination of surface area and porosity. Pure Appl. Chem. 57, 603-619.

Lefebvre Y., Lacelle S. \& Jolicoeur C. (1992) Surface fractal dimensions of some industrial minerals from gas-phase adsorption isotherms. J. Mater. Res. 7, $1888-1891$.

Lippens B.C. \& de Boer J.H. (1965) Studies on pore systems in catalysts. V. The t-method. J. Catal. 4, 319-323.

Mandelbrot B. (1982) The Fractal Geometry of Nature. Freeman, San Francisco.

McKeague J.A. \& Day J.H. (1966) Dithionite- and oxalate-extratable $\mathrm{Fe}$ and $\mathrm{Al}$ as aids in differentiating various classes of soils. Can. J. Soil Sci. 46, 13-22.

Murray R.S. \& Quirk J.P. (1990) Surface area of clays. Langmuir, 6, 122-124.
Oades J.M. (1984) Interactions of polycations of aluminum and iron with clays. Clays Clay Miner. 32, $49-57$.

Quirk J.P. \& Aylmore L.A.G. (1971) Domains and quasi-crystalline regions in clay systems. Soil Sci. Soc. Am. Proc. 35, 652-654.

Rengasamy P. \& Oades J.M. (1977a) Interaction of monomeric and polymeric species of metal ions with clay surfaces. I. Adsorption of iron (III) species. Aust. J. Soil Res. 15, 221-233.

Rengasamy P. \& Oades J.M. (1977b) Interaction of monomeric and polymeric species of metal ions with clay surfaces. II. Changes in surface properties of clays after addition of iron (III). Aust. J. Soil Res. 15, 235-242.

Rutherford D.W., Chiou C.T. \& Eberl D.D. (1997) Effects of exchanged cation on the microporosity of montmorillonite. Clays Clay Miner. 45, 534-543.

Russell J.D. (1979) Infrared spectroscopy of ferrihydrite: evidence for the presence of structural hydroxyl groups. Clay Miner. 14, 109-114.

Schwertmann U. (1979) The influence of aluminum on iron oxides: 5. Clay minerals as sources of aluminum. Soil Sci. 128, 195-200.

Schwertmann U. (1988) Goethite and hematite formation in the presence of clay minerals and gibbsite at $25^{\circ} \mathrm{C}$. Soil Sci. Soc. Am. J. 52, 288-291.

Sing K.S.W. (1967) Assesment of microporosity. Chem. Ind. 20, 829-830.

Srasra E., Bergaya F., Van Damme H. \& Ariguib N.K. (1989) Surface properties of an activated bentonitedecolorisation of rape-seed oils. Appl. Clay Sci. 4, $411-421$.

Thomas J. Jr. \& Bohor B.F. (1968) Surface area of montmorillonite from the dynamic sorption of nitrogen and carbon dioxide. Clays Clay Miner. 16, $83-91$.

Van Damme H. \& Ben Ohoud M. (1990) From flow to fracture and fragmentation in colloidal media. 2 . Local order and fragmentation geometry. Pp. 105-116 in: Disorder and Fracture (J.C. Charmet et al., editors) Plenum Press, New York.

Varadachari C., Mondal A.J. \& Ghosh K. (1991) Some aspects of clay-humus complexation: effect of exchangeable cations and lattice charge. Soil Sci. 151, 220-227.

Washburn E.W. (1921) Note on a method of determining the distribution of pore sizes in a porous material. Proc. Nat. Acad. Sci. U.S.A. 7, 115-116.

Yin Y. (1991) Adsorption isotherm on fractally porous materials. Langmuir, 7, 216-217. 